\title{
Blood and Histopathological Biomarkers of Immune-related Adverse Effects of Treatment with Immune Checkpoint Inhibitors
}

\author{
Yogesh Jheengut, Yi Qian Liu, Ling Xiang Liu \\ Department of Oncology, The First Affiliated Hospital of Nanjing Medical University, Nanjing, Jiangsu 210029, China.
}

\begin{abstract}
Immune checkpoint inhibitors have been a recent major breakthrough in the management of tumors. They have broadened the scope of management in medical oncology, which has been heavily dependent on chemotherapy. Immune checkpoint inhibitors have renewed the hope of many patients for a more effective treatment. However, Immune checkpoint inhibitors are also associated with a variety of adverse effects, most commonly immunerelated adverse events, and these are often different from the known chemotherapy-induced toxicities. Hence, there is a need to identify specific biomarkers which are able to predict or diagnose these immune-related adverse events.
\end{abstract}

Key words: Immune checkpoint inhibitors; Immune related adverse effects; Cytotoxic T-lymphocyte-associated protein 4; Programmed cell death-1; Programmed death-ligand 1

\section{Introduction}

Anti-cytotoxic T-lymphocyte-associated protein 4 (CTLA-4), anti-programmed cell death protein 1 (PD-1) antibodies and anti-programmed cell death 1 ligand (PDL1) antibodies are immune checkpoint inhibitors (ICI) currently being used for the treatment of many cancers, including metastatic melanoma, non-small cell lung carcinoma, renal cell carcinoma and colorectal cancer. The ICI can be used either alone or in combination with other therapies. However, by disrupting the balance or the control of the immune system, these immune checkpoint inhibitors, can also generate autoimmune toxicities, which mainly involve the gut, skin, endocrine glands, liver, and lungs, but can affect any tissue. This review, provides an overview of the latest and most relevant blood and histopathological biomarkers which can be used to predict or detect the organ specific adverse effects following the use of ICI. Where appropriate, other biomarkers that can be used to detect or predict organ specific adverse effects are described.

\section{Types of ICI-related Adverse Effects according to the Organ Site, and Corresponding Biomarkers Dermatological toxicity}

Dermatological toxicities are the most common adverse effects. Ipilimumab treatment is more likely to cause dermatological issues compared to antiPD-1 agents [1]. Dermatological toxicity is usually the earliest adverse effect, especially in patients receiving ipilimumab [2].

Corresponding author: Ling Xiang Liu, MD, PhD, Department of Oncology, The First Affiliated Hospital of Nanjing Medical University, 300 Guangzhou Rd., Nanjing, Jiangsu 210029, China; Tel: +86 256830 6714; Email: 1lxlau@163.com.

\section{Blood biomarkers}

It has been reported that patients who develop skin toxicity while using ICI, usually have a higher absolute eosinophil count (AEC) in the peripheral blood compared to their baseline level [3,4]. Moreover, Schindler et al found that the incidence of toxicity was higher as the absolute eosinophil count increased. He reported that in patients with melanoma who were treated with ipilimumab, the incidence of skinir AEs was higher when the absolute eosinophil count was higher at weeks 4 and 7 after the start of treatment [3]. Hence, the absolute eosinophil count is a good biomarker not only for detecting skin toxicity, but it can also be used to predict the severity of the dermatological toxicity.

\section{Histopathology}

A skin biopsy is usually done for any atypical, severe, persistent, recurrent or poorly tolerated rash following ICI treatment [1]. Histopathological examinations of skin biopsies from many patients have shown the presence of perivascular lymphocytic infiltrates going deep into the dermis, patchy necrotic keratinocytes, and few to a large number of eosinophils [1] with $\mathrm{CD} 4^{+}$and $\mathrm{CD} 8^{+} \mathrm{T}$ cells in close proximity to melanocytes $[4,5]$.

Other characteristic histopathologic aspects can be similar to those seen in patients with psoriasis, Grover's disease, bullous pemphigoid, and granulomatous sarcoidlike dermatitis. Less commonly, a lichenoid reaction can be seen, and this is particularly common with anti-PD-1/PDL1 agents [1].

Some patients may have vitiligo like lesions, but these lesions have a different pathophysiological mechanism, as reported by Larsabal $\mathrm{M}$ et al. They recently reported that the vitiligo-like lesions that develop as adverse effects of ICI differ histologically, particularly with regard to the presence ofskin infiltration by $\mathrm{CD} 8^{+}$T-cells expressing C-X-C motif receptor 3 , which is not seen in true vitiligo [6]. 
In one case, neutrophilic infiltration diagnostic for Sweet syndrome was seen [7].

In clinical practice, an increased eosinophil count from baseline or eosinophilia as a specific blood biomarker and/or with specific histopathological examination of a mucocutaneous lesion may be used as a potential biomarker to predict or diagnose early skin irAEs. This will help to initiate early treatment and thus, prevent the development of severe toxicity for the patients.

\section{Gastrointestinal toxicity [colitis]}

Diarrhea/colitis most commonly presents approximately six weeks into treatment, which is later than dermatologic toxicity, which is why suspicion for immune-mediated colitis should remain high for the first several months $[8,9]$.

\section{Blood biomarkers}

IL-17 family cytokines have been linked to many immune and autoimmune-related diseases. It has been demonstrated that patients onipilimumab, with inflammatory colitis following treatment with ipilimumab have higher serum IL-17 levels compared to baseline [10].

Another recent trial concluded that female patients and those with lower serum IL-6 (compared to the baseline serum level), were at higher risk of developing grade 3-4 gastrointestinal toxicity following treatment with ipilimumab [11].

Fujisawa $\mathrm{Y}$ et al. showed a correlation between changes in routine blood count values with the occurrence of serious irAEs or lung/gastrointestinal toxicity in patients with melanoma who were treated with nivolumab [12]. Both an increased white blood cell (WBC) count and decreased relative lymphocyte count (RLC) were associated with gastrointestinal (G.I) irAE [12].

Berman D et al.,reported that ipilimumab induces antibodies to enteric flora, such as pANCA (perinuclearstaining anti-neutrophil cytoplasmic antibody) and $\mathrm{OmpC}$ [outer membrane protein complex). These antibodies are markers of an unbalanced mucosal immune environment and it was found that the majority of patients with grade 2 or higherirAEs, had a positive titer foranti-pANCA and antiOmpC antibodies [13].

Another prospective study showed that there is a relationship between the gene expression profile in whole blood samples and the gastrointestinal side effects due to ICI. For example, neutrophil activation markers (CD117 and CEACAM1 gene expression) might have a predictive role for G. I toxicity. An increase in CD117 and CEACAM1 gene expression, along with an increase in the peripheral absolute neutrophil count, were found to be early predictors for gastrointestinal immune related side effects [14].

\section{Stool biomarkers}

Intestinal infection should be always considered as a differential diagnosis in patients under immunotherapy with diarrhea. Stool should be collected for bacterial culture or multiplex nucleic acid amplification testing (NAAT), to rule out any gastrointestinal pathogens (e.g. Clostridium difficile). If multiplex NAAT is not available, testing for ova and parasites and other pathogens should be performed [15].

\section{Fecal calprotectin}

Although there is no specific stool laboratory test to diagnose irAEs in the colon, there is a non-invasive laboratory test, called the fecal Calprotectin test, which detects a fecal proteinin stool. Fecal calprotectin is derived mostly from neutrophils, that have migrated into the intestinal mucosa during intestinal inflammation, and the level pf calprotectin can be used as a biomarker of bowel inflammation [16]. Appositive fecal calprotectin test or an increased level of fecal calprotectin, indicates the presence of intestinal inflammation, but the exact site affected cannot be determined by this test alone. Moreover, despite its high sensitivity and specificity for intestinal inflammation, it is not specific for ICI induced colitis [13].

\section{Endoscopy and Histopathology Endoscopic findings}

The typical endoscopic findings of ICI induced colitis range from normal to those seen in inflammatory bowel disease, including loss of the vascular pattern, exudates, granularity, friability, and ulcerations. These changes are typically, but not always, continuous [17]. Gupta A et al. reported diffuse inflammatory changes such as exudates, granularity, loss of vascular pattern and ulcerations on lower GI endoscopy in patients who had colitis associated with anti- CTLA-4 therapy [18]. In another study where patients received ipilimumab treatment, it was seen that inflammatory changes may already be present in the colon, before the patients experience symptoms of have gastrointestinal toxicity [19].

\section{Histopathology}

The most common observation in the colon is the presence of intraepithelial neutrophilic leukocytes (IENL), between the surface epithelial cells and between the crypt epithelium. There may also be an increase in lamina propria cellularity, with a particular increase in mononuclear cells [17]. Other findings that can be seen are crypt architectural distortion, neutrophilic crypt abscesses, increased apoptosis, features of ischemic colitis, and collagenous colitis [20].

Histopathological features in colon samples from patients receiving both anti-PD1 and CTLA-4 inhibitors are not well documented [21].

\section{ICI induced side effects outside the colon}

Gastrointestinal toxicity may also be seen outside the colon, with toxicity observed in the stomach, duodenum and 
ileum. Upon histopathological examination, the changes observed in the gastric mucosa included lamina propria expansion and intraepithelial neutrophils. Duodenal and ileal biopsies commonly showed lamina propria expansion by lymphoplasmacytic infiltrates and eosinophils, villous blunting, intraepithelial lymphocytes, and neutrophilic villitis. Increased apoptosis was a rare and variable finding in gastric, duodenal, or ileal biopsies in different studies [2022].

In summary, diarrhea is an important symptom to monitor in patients receiving immunotherapy. The first step should always be ruling out any infectious causes. Quantitation of the serum IL-17 cytokine level, along with a full blood count test, should be done at baseline and after the initiation of ICI. Any increase in the IL-17 serum level with an associated increase in the white blood cell (WBC) count and a decrease in the RLC following use of ICI is considered to indicate an immune related gastrointestinal toxicity, especially in the colon. Additional diagnostic findings may include elevation of the anti-pANCA and anti OmpC antibody titers, increase in the gene expression neutrophil activation markers (CD117 and CEACAM1), and a decrease in the serum IL6 cytokine level compared to the baseline level. These may serve as early predictors for gastrointestinal toxicity secondary to ICI. Endoscopy may be done to determine the extent of the colitis and also to detect any extra colonic ICI induced abnormalities, such as in the stomach or ileum. A histopathological examination of colonic biopsy will be useful for diagnosing gastrointestinal irAEs. A stool fecal calprotectin test may be used to monitor improvement inflammation, with serial measurements of the fecal calprotectin level before and during the use of ICI (or during treatment of the toxicity) able to determine whether there is improvement in the inflammation. The serum cytokine levels and anti-pANCA and OmpC antibody titers, may be measured by ELISA based methods. Gene expression can be determined by quantitative PCR method.

\section{Hepatotoxicity}

Liver toxicity is commonly seen at 8 to 12 weeks after the start of ICI treatment, although early or delayed events may also be seen [2].

\section{Blood biomarkers}

Liver function tests (LFT's) should be done before starting any ICI treatment, and it is advisable to repeat the LFT's before each cycle, so that any liver toxicity is diagnosed as early as possible.

An unexplained elevation of the alanine transaminase (ALT) and aspartate transaminase (AST) levels following the use of ICI, may indicate immune related hepatitis. Hepatotoxicity can also cause elevated alkaline phosphatase (ALP) and total bilirubin levels $[23,24]$. The next cycle of ICI may be withheld if there is persistent AST or ALT elevation by more than 3 times the upper limit of normal, or a persistent total bilirubin more than 1.5 times the upper limit of normal. However hepatic infection or malignant causes must always be ruled out [25].

\section{Histopathology \\ Liver biopsy}

To correctly diagnose autoimmune hepatotoxicity, and to exclude a metastatic lesion, it is necessary to perform a liver biopsy. A liver biopsy showing diffuse T-cell infiltrates in all lobes, prominent sinusoidal histiocytic infiltrates and central vein damage with endotheliitis is considered to be diagnostic of autoimmune hepatotoxicity [24].

Immune related hepatotoxicity with abnormal liver function may be asymptomatic in many patients. Nevertheless, when there is even a small elevation in the levels of liver enzymes like ALT and, AST in the absence of other conditions like liver infection and malignancy, liver toxicity secondary to ICI treatment should be suspected. A liver biopsy can be performed to confirm the diagnosis of autoimmune hepatotoxicity.

\section{Lung toxicity (pneumonitis)}

Pneumonitis is a difficult condition to diagnose and is usuallyfatal. It is typically a diagnosis of exclusion. As in the investigation for liver toxicity, it is always necessary to rule out any infectious or malignant factors that may be causing pneumonitis.

\section{Blood biomarkers}

As mentioned previously, an increase in the WBC count and a decrease in the RLC are associated with lung/ G.I irAE [12].Therefore, these changes in peripheral blood parameters, can also be used to detect lung toxicity due to ICI use.

The serum levels of circulating cytokines including CXCL2 (C-X-C motif chemokine ligand 2), IL 1 ra (interleukin-1 receptor antagonist) and IL2ra (interleukin-2 receptor alpha chain), can be assessed as predictive biomarker for pneumonitis. CXCL2 is produced by monocytes and macrophages and it attracts neutrophils and other immune cells during inflammatory processes [26]. Circulating IL1ra and IL2ra are also part of a gene signature that is predictive for lung toxicity in patients treated with ICI [27]. Hence, when there are increases in the serum CXCL2, IL1ra and IL2ra levels compared to the baseline level during or subsequent to ICI use, they can be considered an early predictor for pneumonitis [28].

\section{Histopathology}

Naidoo $\mathrm{J}$ et al. examined tissue samples from patients treated with ICI and found cellular interstitial pneumonitis, organizing pneumonia, and diffuse alveolar damage [29]. 
Bronchoscopy may also show a diffuse lymphocytic infiltrate on biopsy and brushings [30].

Although pneumonitis is a relatively uncommon irAEs compared to dermatological or gastrointestinal toxicity, it should be promptly diagnosed, as it may be fatal for the patient. A full blood count analysis showing an increased WBC count and a decreased RLC, should be considered to suggest lung toxicity. Moreover, monitoring the serum levels CXCL2, IL1ra and IL2ra may permit an early diagnosis of this toxicity. However, to confirm the diagnosis, a lung biopsy must be performed. Since this is difficult or impossible to perform in many patients, pneumonitis remains a diagnosis of exclusion in clinical practice.

\section{Endocrinopathy Secondary to Treatment with an Immune Chekpoint Inhibitor Hypophysitis}

Hypophysitis is a rare condition characterized by inflammation of the pituitary gland, usually resulting in hypopituitarism and pituitary enlargement [31]. Pituitary inflammation can occur as a primary hypophysitis (most commonly due to lymphocytic, granulomatous or xanthomatous disease) or as secondary hypophysitis (as a result of systemic diseases, immunotherapy or alternative sella-based pathologies) [32].

\section{Blood biomarkers}

Pituitary hormone testing involves full early morning pituitary related hormonal profile, which should include ACTH (adrenocorticotropic hormone), GH (growth hormone), estradiol (for pre-menopausal females), testosterone (in males), LH (luteinizing hormone), FSH (follicle stimulating hormone), free thyroxine, TSH (thyroid stimulating hormone), prolactin, plasma/ urine osmolality and, electrolyte levels. Hypophysitis is known to present with isolated or combined deficiency of ACTH,TSH, gonadotropins (LH,FSH) and GH [33]. The Prolactin level has been reported to be decreased in patients with autoimmune hypophysitis, but rare cases with high prolactin levels, have also been reported [34,35].

Patients who develop nocturia, polydipsia, and/or polyuria after starting ICI, should be screened for central diabetes insipidus (posterior pituitary hypophysitis). A low urine osmolality, high serum osmolality and a low urine specific gravity can diagnose central diabetes insipidus. There can also be an abnormal blood electrolyte level, especially, hypernatremia. The blood level of antidiuretic hormone $(\mathrm{ADH})$ will also be decreased in patients with central diabetes insipidus [36].

\section{Histopathology}

Although difficult to perform, a histopathological analysis, is required to confirm a diagnosis of hypophysitis [37]. Caterugli $\mathrm{P}$ et al. examined the biopsy findings of
CTLA-4 related hypophysitis, and noted complement fixation, macrophage infiltration and lymphocyte activation in the pituitary gland [38].

There should be a high level of suspicion for hypophysitis, especially in males with a new onset headache or visual disturbances following the use of ICI cell [39]. Histopathological confirmation of hypophysitis is not routinely done as it is difficult and risky, so the diagnosis is often presumptive rather than confirmed. Baseline and regular blood testing during treatment can help to diagnose hypophysitis early in the course of the disease. A finding of combined low ACTH, low TSH, low gonadotropin and low growth hormone level is considered to suggest this toxicity. Although posterior pituitary hypophysitis is rarer than anterior hypophysitis, it is associated with specific symptoms like increased thirst, increased urine volume or frequent nocturnal urination in patients receiving ICI treatment. If patients are symptomatic, they should be screened for diabetes insipidus as soon as possible, as an early diagnosis permit earlier treatment and can prevent severe toxicity or lifelong hypophysitis. The hormone levels can be measured by routine immunoassays.

\section{Thyroid toxicity}

Patients with thyroid dysfunction secondary to ICI mayinitially present with either thyrotoxicosis or hypothyroidism. While thyrotoxicosis can frequently be followed by hypothyroidism, there have not been any cases of hypothyroidism followed by thyrotoxicosis [40].

\section{Hypothyroidism \\ Blood biomarkers}

It is important to distinguish primary hypothyroidism from secondary hypothyroidism (typically a result of hypophysitis). Patients with primary hypothyroidism will show a high thyroid-stimulating hormone (TSH) level with low free thyroxine $\left(\mathrm{T}_{4}\right)$ or low triiodothyronine $\left(\mathrm{T}_{3}\right)$ levels, as well as a high thyroid peroxidase (TPO) and thyroglobulin antibody titers [41,42]. However, a low TSH with low free $\mathrm{T}_{4}$ will indicate hypothyroidism secondary to hypophysitis [41,43].

\section{Thyrotoxicosis \\ Blood biomarkers}

Thyrotoxicosis is caused by thyroiditis, and can be diagnosed based on a low thyroid stimulating hormone (TSH) level in conjunction with elevation of at least one of three thyroid hormones: total thyroxine $\left(\mathrm{T}_{4}\right)$, free $\mathrm{T}_{4}$, or free triiodothyronine (FT3) [40].

\section{Histopathology}

A histopathological examination may show lymphocytic infiltration by both B cells and cytotoxic T cells, particularly in patients treated with anti PD-1 ICI [44]. 
It is recommended that a baseline thyroid function test should be performed for each patient prior to starting ICI, and testing should be repeated regularly during treatment, as many patients may not have typical symptoms of thyroid dysfunction. Although it is not commonly performed, thyroid gland biopsy and histopathological examination, can confirm any thyroid toxicity. Immunoassay techniques, may be used to measure the hormone levels and thyroid antibody titers.

The most critical endocrinopathy that may occur following ICI treatment is adrenal insufficiency, which can cause dehydration, hypotension, and electrolyte imbalances (hyperkalemia, hyponatremia). Primary adrenal insufficiency constitutes a medical emergency. However, autoimmune adrenalitis is a rare toxicity, although higher rates are observed when patients are treated with combined ICI [45].

\section{Blood biomarkers}

If adrenal failure due to autoimmune adrenolytic is suspected, the serum levels of cortisol, ACTH (adrenocorticotrophic hormone), aldosterone and renin must be evaluated. An early morning serum cortisol level of less than $250 \mathrm{nmol} / \mathrm{L}$ together with an elevated ACTH level, strongly suggests adrenal insufficiency. The ACTH level can also be used to distinguish between PAI, in which ACTH is high, and secondary adrenal insufficiency due to pituitary impairment (hypophysis), in which ACTH is low and associated with a low cortisol level. An elevated renin level and a low level of aldosterone will also indicate PAI. Serum electrolyte testing may show hyponatremia or hyperkalemia [46,47].

A pre-stimulus cortisol test (also known as an ACTH stimulation test) with the administration of cosyntropin, [a synthetic form of adrenocorticotropic hormone (ACTH)], that shows no change, will help to diagnose PAI and may exclude a secondary adrenal failure. A patient with secondary adrenal failure due to hypophysitis, will show a positive or high cortisol level in response to cosyntropin administration [47]. PAI is a medical emergency that can have fatal consequences if not treated in time. Clinicians should always be on alert for early symptom of PAI, and must be able to diagnose adrenalitis effectively. The Hormone levels may be assessed by routine immunoassays. The renin activity and aldosterone level can be measured by ELISA or radioimmunoassay.

\section{Diabetes Mellitus}

\section{Type 1 diabetes mellitus}

There is strong evidence that an insulin-deficient type of diabetes can develop following the with use of ICI [48].

\section{Blood biomarkers}

Patients may present with a high plasma glucose level, elevated $\mathrm{HbA} 1 \mathrm{c}$ and also an inappropriately low or undetectable serum C-peptide level. Some patients may also have positive autoantibodies to diabetes autoantigens, such as a markedly elevated antiGAD65 titer [48]. However, these autoantibodies have not been definitively linked to ICI. Highserum lipase, serum amylase, and elastase levels can also be investigated as possible markers indicative of pancreatic inflammation. In clinical practice, non-diabetic patients under treatment with ICI who have acute severe hyperglycemia with ketoacidosis or low/undetectable C-peptide levels already have strong evidenceof diabetes mellitus, and appropriate measures should be started as soon as possible.Diabetes autoantibodies may be detected by immunoprecipitation using Protein A Sepharose.

\section{Other Immune-related Adverse Effects Renal toxicity}

Acute kidney injury (AKI) has also been reported as possible complication of checkpoint inhibitor immunotherapy, but it appears to be rare [49].

\section{Blood biomarkers}

The baseline serum creatinine level should be evaluated at the start of ICI and should be rechecked at every cycle to detect even a small rise in the serum creatinine level, as this could indicate renal toxicity. There may also be hypoalbuminemia, which is consistent with nephrotic like syndrome [49].

A disturbance of the serum electrolyte levels is very common in renal failure. However, the most common disturbance seen due to the use of ICI is hyponatremia, which is commonly related to pan hypopituitarism [50]. Serum testing may also reveal the presence of anti-doublestranded DNA and antinuclear antigen antibodies [51].

\section{Urine biomarkers}

In an $24 \mathrm{~h}$ urine sample, there may be sub-nephrotic proteinuria at the time of diagnosis for acute kidney injury diagnosis [49]. Urine microscopy may show red blood cells, sterile pyuria and WBC casts which is suggestive of an intrinsic inflammatory kidney lesion [51].

\section{Histopathology}

Kidney biopsy is recommended to define the underlying lesion when the cause of AKI is unclear [51]. The most common biopsy finding reportedis acute interstitial nephritis (AIN) [50,52]. Podocytopathies, such as lupus like nephritis, minimal change disease, and TMA (thrombotic microangiopathy) have also been seen after ipilimumab therapy [50].

As noted above, acute kidney injury is a rare complication of checkpoint inhibitor immunotherapy. However, affected patients, can end up with severe renal injury, which may require the discontinuation of checkpoint inhibitor immunotherapy and treatment with 
corticosteroids. In order to detect renal toxicity early in the course of disease, blood biomarkers should be examined in all patients, and testing should be repeated regularly during immunotherapy with ICI.

\section{Pancreatic Toxicity Blood biomarkers}

Elevated levels of serum amylase and lipase have been reported in many patients in trials of cytotoxic T-lymphocyte-associated antigen 4 (CTLA-4) and PD-1 blockade, but these laboratory findings do not fulfill the criteria for acute pancreatitis, and most of these patients were asymptomatic $[53,54]$.

\section{Cardiotoxicity}

Cardiotoxicity is a rare complication, but can be fatal. Therefore, an early diagnosis can help save the life of patients who develop cardiotoxicity while on ICI therapy.

\section{Blood biomarkers}

The levels of high-sensitivity troponin T (hs-TnT) and BNP (brain natriuretic peptide level), can be elevated in some cases of cardiotoxicity due to ICI. Additionally, CKMB (creatine kinase-myocardial band)may also be elevated $[55,56]$, supporting the diagnosis of cardiotoxicity.

\section{Histopathology}

The currently accepted gold standard for diagnosis requires end myocardial biopsy. There is a predominance of lymphocytic infiltration of cardiac tissue, seen in patients treated with anti PD-1 and CTLA-4 inhibitors, especially by $\mathrm{T}$ cells that are clonally similar to the tumor reactive $\mathrm{T}$ cells [57].

\section{Hematological toxicity}

Immune checkpoint inhibitors are not direct inhibitors of cell replication. Rarely, hematological dyspraxia, hemolytic anemia and myelodysplastic syndrome have been described in patients treated with PD-1 or PD-L1 inhibitors [58,59]. Full blood counts and blood films may show red cell aplasia, neutropenia, and thrombocytopenia especially in following treatment with the CTLA-4 inhibitor, ipilimumab. Hemophilia screening may show acquired hemophilia $\mathrm{A}$, and the cryoglobulin test may show cryoglobulinemia [60].

\section{Rheumatological complications}

irAEs vary substantially. The diagnosis is primarily made clinically, based on the patient's history and a physical examination showing new-onset arthritis following the initiation of an ICI.

\section{Blood biomarkers}

Many patients can become seropositive for rheumatoid factor (RF) and cyclic citrullinated peptide (CCP) following the initiation of ICI treatment, but some patients may also remain seronegative for these tests despite rheumatologically toxicity [61].

An elevated erythrocyte sedimentation rate (ESR) and C-reactive protein (CRP) level may be present, although the utility of these markers to identify inflammatory arthritis is compromised by the presence of comorbid malignancy, which may also affect the levels of ESR and CRP.

\section{Neurological toxicity}

Neurological disorders that can develop following ICI treatment may include meningoencephalitis, limbic encephalitis, cranial polyneuropathy, myasthenia syndrome and myositis [62].

\section{Biomarkers and biopsy findings}

Blood tests may show markedly elevated creatine phosphokinase $(\mathrm{CPK})$ in patients experiencing muscle weakness due to neurological toxicity. The CRP level may also be elevated, and along with a high CPK level, would indicate acute muscle inflammation. Muscle biopsy may reveal abnormalities like necrotic muscle fibers with infiltration by T-lymphocytes and macrophages [62].

The CSF (cerebrospinal fluid) cytology may reveal abnormal cells like mononuclear pleocytosis, as are observed in meningoencephalitis. CSF biochemistry may show abnormalities including an elevated protein but normal glucose levels [62].

\section{Performance score and irAEs}

Many patients with poor Eastern Cooperative Oncology Group (ECOG) performance status who are, receiving cytotoxic chemotherapy have been found to have significant toxicities, a poor quality of life, and a shorter lifespan. However, even patients with a poor performance status who are being treated, using immune checkpoint inhibitors, specifically anti-PD1/PD-L1 monotherapy, often have low rates of adverse effects and a better toxicity profilecompared with the use of cytotoxic chemotherapy [63]. Hence, ICI may be used even in patients with a poor performance status.

\section{Sarcopenia and irAEs}

Sarcopenia, is a syndrome characterized by a decrease in skeletal muscle mass and strength. It is associated with physical disability, a poor quality of life and death [64]. It may be a physiological change of aging or can also develop as a result of poor nutritional status.

Sarcopenia has been found to have an effect on the toxicity profile of immune checkpoint inhibitors, as it has been reported that patients with sarcopenia, experience higher rates of immune related adverse effects. In a Frenchstudy, it was found that there was a higher rate 
of any-grade toxicity in sarcopenic patients, leading to treatment cessation [65].

In an another study in patients with melanoma treated with an anti-PD-1 agent, it was observed that over weight women with sarcopenia, had 6.5-fold increased risk of developing adverse effects, which led to a definitive cessation of treatment [66].

Therefore, it is advisable to payattention to patients with poor skeletal muscle mass and/or, poor strength even when the patients are overweight or obese, as they have a higher risk for toxicity following ICI treatment, especially treatment with PDL-1 inhibitors. Moreover, sarcopenic patients need appropriate nutritional care, designed by experienced professionals (such as nutritionists), to build up their skeletal muscle mass and strength, so that they can better tolerate the treatment with ICI.

Table 1 provides a summary of the main blood and histopathological biomarkers that can be used in clinical practice, to identify or predict the irAEs. Where appropriate, other useful clinical biomarker, are included.

Table 1 Blood and histopathological biomarkers for irAEs.

\begin{tabular}{|c|c|}
\hline Blood biomarker [s] & Histopathological findings \\
\hline $\begin{array}{l}\text { Dermatologi- FBC: Increased AEC or eosinophilia. }[3,4] \text {. } \\
\text { cal Toxicity }\end{array}$ & $\begin{array}{l}\text { Skin biopsy: Perivascular lym- } \\
\text { phocytic infiltration deep into the } \\
\text { dermis. Patchy necrotic kerati- } \\
\text { nocytes. Skin infiltration by CD } 8 \\
\text { cells expressing CXCR3 }[1,4-6] \text {. }\end{array}$ \\
\hline
\end{tabular}

Colitis $\quad$ FBC: Increased WBC count. Decreased RLC [12]. Colonic biopsy: Presence of Fecal calprotectin Serum cytokines: Increased serum IL17 [10]. Decreased intraepithelial neutrophilic leuco- test: Positive [15]. serum IL6 [11]. $\quad$ cytes (IENL).

Antibodies: High anti-pANCA and anti-OmpC. antibody Increase in lamina propria cellulartiters [13].

Gene expression level: Increased neutrophil activation ity $[17,20]$. markers (CD117 and CEACAM1) [14].

Hepatotoxic- Liver Function test: High ALT level. High AST level. Liver biopsy: Diffuse T-cell infility High ALP level. High total bilirubin level $[23,24]$. tration in all lobes, prominent sinusoidal histiocytic infiltrates, $\mathrm{CV}$ endotheliitis [24].

Pneumonitis FBC: Increased WBC count. Decreased RLC. [12].

Lung biopsy: Cellular interstitial Serum cytokine levels: Increased serum CXCL2, IL1ra pneumonitis, organizing pneuand IL2ra levels [12] [26-28]. monia, diffuse alveolar damage or diffuse lymphocytic infiltrates $[29,30]$.

Hypophysitis Ant hypophysitis: Low GH,low ACTH, low TSH, low Pituitary gland biopsy: Complegonadotropins (estradiol, LH and FSH). Low or high pro- mentfixation, macrophage infillactin level [33-35].

Posthypophysitis: Low ADH level. Low urine osmo- [38]. lality. Highserum osmolality. Low urine specific gravity. Hypernatremia [36].

Thyroid Primary hypothyroidism: High TSH, low $\mathrm{T}_{4}$, low $\mathrm{T}_{3}$, Thyroid gland biopsy:

toxicity high TPO and Th Ab $[41,42]$ Lymphocytic infiltration by both B Secondary hypothyroidism: Low TSH, low $\mathrm{T}_{4}$. Thyrotoxicosis: Low TSH, high level oftotal $\mathrm{T}_{4}$, free $\mathrm{T}_{4}$ and/or free FT3 [40].

Adrenalitis Primary AI: Low cortisol level. High ACTH level. Low [primary ALD level. High renin level. Pre-stimulus cortisol test: adrenal insuf- NEG [46,47].

ficiency] Secondary AI: Low cortisol, low ACTH. Pre-stimulus cortisol test: POS [47].

Diabetes High plasma glucose level. High HbA1c level.

mellitus Low or undetectable c-peptide level. Positive autoantibodies to diabetes autoantigens [48].

High serum lipase, amylase and elastase levels.

Renal High serum creatinine level. Low Alb level.

Renal biopsy: AIN (most com- Sub-nephrotic proteintoxicity Low sodium level. Positive anti-dsDNA, ANA antibodies [49-51]. cells and cytotoxic T cells [44].

mon), podocytopathies (lupus-like uria [49], nephritis, minimal change disease, Pyuria, RBC and/or TMA) [50,52]. $\mathrm{WBC}$ in urine [51].

Pancreatic High Serum amylase and lipase levels [53,54]. toxicity 
Table 1 (Continued)

\begin{tabular}{|c|c|c|}
\hline$\overline{\operatorname{irAE}}$ & Blood biomarker[s] & Histopathological findings \\
\hline $\begin{array}{l}\text { Cardiotoxici- } \\
\text { ty }\end{array}$ & High hs-TnT and BNP levels, high serum CKMB $[55,56]$. & $\begin{array}{l}\text { Cardiac biopsy: lymphocytic in- } \\
\text { filtration (T clonal cells) [57]. }\end{array}$ \\
\hline $\begin{array}{l}\text { Hematologi- } \\
\text { cal toxicity }\end{array}$ & $\begin{array}{l}\text { FBC: Red cell aplasia, neutropenia, thrombocytopenia } \\
\text { [60]. } \\
\text { Hemophilia screening test: Hemophilia A [60]. } \\
\text { Cryoglobulin test: Cryoglobulinemia [60]. }\end{array}$ & \\
\hline $\begin{array}{l}\text { Rheumato- } \\
\text { logic toxicity }\end{array}$ & Seropositive for RF and CCP [61]. & \\
\hline $\begin{array}{l}\text { Neurological } \\
\text { toxicity }\end{array}$ & High CPK level. High CRP level [62]. & $\begin{array}{l}\text { Muscle biopsy: Abnormalities like CSF:Abnormal cells } \\
\text { necrotic muscle fibers with infiltra- (mononuclear pleocy- } \\
\text { tion by T-lymphocytes and macro- tosis). High protein, } \\
\text { phages }[62] . \\
\text { normal glucose levels } \\
{[62] .}\end{array}$ \\
\hline
\end{tabular}

Note: AEC, Absolute eosinophil count; anti-pANCA: Anti-perinuclear-staining anti-neutrophil cytoplasmic antibody; anti-OmpC: Anti-outer membrane protein complex; ALT: Alanine transaminase;AST:Aspartate transaminase; ALP:Alkaline phosphatase; Ant: Anterior; ADH: Antidiuretic hormone; ACTH: Adrenocorticotropic hormone; AI:Adrenal insufficiency; ALD: Aldosterone; Alb: Albumin; ANA: Antinuclear antigen antibodies; AIN: Acute interstitial nephritis;BNP: Brain natriuretic peptide; CKMB: CreAtine kinase-myocardial band; CCP: Cyclic citrullinated peptide; CPK: Creatine phosphokinase; CRP: C-reactive protein; CSF: Cerebrospinal fluid; CV: Central vein; CXCL2: C-X-C motif chemokine ligand 2; CXCR3: C-X-C motif receptor 3; dsDNA: Double-stranded DNA; FBC: Full blood count;FT3: Free triiodothyronine; FSH: Follicle stimulating hormone; GH: Growth hormone; $\mathbf{H b A}_{\mathbf{1 c}}$ Hemoglobin-A ${ }_{1 \mathrm{c}}$; Hs-TnT: High-sensitivity troponin T; IL17: Interleukin 17; IL 6: Interleukin 6; IL1ra: Interleukin-1 receptor antagonist; IL2ra: Interleukin-2 receptor alpha chain; LH: luteinizing hormone; NEG: Negative; Post: Posterior; POS: Positive; RLC: Relative lymphocyte count; RF: Rheumatoid factor; RBC: Red blood cells; RLC: Relative lymphocyte count;TSH: Thyroid stimulating hormone; TPO: Thyroid peroxidase; Th: Thyroglobulin; $\mathbf{T}_{4}$ : thyroxine; TMA: Thrombotic microangiopathy; WBC: White blood cell.

\section{Conclusion}

Immune checkpoint inhibitors have shown efficacy against several types of tumors. Although these agents are generally safer than other cytotoxic drugs, ICI is associated with several types of toxicity. Oncologists, should always be alert for early symptoms and need to watch for signs of toxicity due to immunotherapy. A detailed laboratory analysis should be performed at baseline (before the patient start treatment) and then regularly during treatment, because there are a variety of biomarkers that can aid in the early recognition of toxicity, improving the treatment and potentially allowing for reversal of these toxicity. Some biomarkers (or combinations of biomarkers), such as the expression of certain genes or levels of some cytokines, should be evaluated in clinical trials, so that they can be applied more effectively in future clinical practice.

\section{Conflict of Interests}

The authors declare no conflict of interests.

\section{Funding}

This work was supported by the National Natural Science Foundation of China [No. 81472782], Natural Science Foundation of Jiangsu Province [BK20141491].

\section{References}

1. Sibaud V. Dermatologic reactions to immune checkpoint Inhibitors: Skin Toxicities and Immunotherapy. Am J Clin Dermatol 2018;19(3):345-61.

2. Weber JS, Kahler KC, Hauschild A. Management of immune-related adverse events and kinetics of response with ipilimumab. J Clin Oncol 2012;30(21):2691-7.

3. Schindler K, Harmankaya K, Kuk D, Mangana J, Michielin O, Hoeller C,Pehamberger H, Wolchok J, Postow M. Correlation of absolute and relative eosinophil counts with immune-related adverse events in melanoma patients treated with ipilimumab. J Clin Oncol 2014;32(15 suppl):9096.

4. Jaber SH, Cowen EW, Haworth LR, Booher SL, Berman DM, Rosenberg SA, Hwang ST. Skin reactions in a subset of patients with stage IV melanoma treated with anti-cytotoxic T-lymphocyte antigen 4 monoclonal antibody as a single agent. Arch Dermatol 2006;142(2):166-72.

5. Hodi FS, Mihm MC, Soiffer RJ, Haluska FG, Butler M, Seiden MV, Davis T, Henry-Spires R, MacRae S, Willman A, Padera R, Jaklitsch MT, Shankar S, Chen TC, Korman A, Allison JP, Dranoff G. Biologic activity of cytotoxic T lymphocyte-associated antigen 4 antibody blockade in previously vaccinated metastatic melanoma and ovarian carcinoma patients. Proc Natl Acad Sci USA 2003;100(8):4712-7.

6. Larsabal M, Marti A, Jacquemin C, Rambert J, Thiolat D, Dousset L, Taieb A, Dutriaux C, Prey S, Boniface K, Seneschal J. Vitiligo-like lesions occurring in patients receiving anti-programmed cell death-1 
therapies are clinically and biologically distinct from vitiligo. J Am Acad Dermatol 2017;76(5):863-70.

7. Pintova S, Sidhu H, Friedlander PA, Holcombe RF. Sweet's syndrome in a patient with metastatic melanoma after ipilimumab therapy. Melanoma Res 2013;23(6):498-501.

8. Prieux-Klotz C, Dior M, Damotte D, Dreanic J, Brieau B, Brezault C, Abitbol V, Chaussade S, Coriat R. Immune checkpoint inhibitor-induced colitis: diagnosis and management. Target Oncol 2017;12(3):301-8

9. Weber JS, Dummer R, de Pril V, Lebbe C, Hodi FS. Patterns of onset and resolution of immune-related adverse events of special interest with ipilimumab: detailed safety analysis from a phase 3 trial in patients with advanced melanoma. Cancer 2013;119(9):1675-82.

10. Callahan MK, Yang A, Tandon S, Xu Y, Subudhi SK, Roman RA, Heine I, Pogoriler E, Kuk D, Panageas K, Yuan JD, Allison JP, Wolchok JD. Evaluation of serum IL-17 levels during ipilimumab therapy: correlation with colitis. J Clin Oncol 2011;29(15_suppl):2505.

11. Valpione S, Pasquali S, Campana L, Mocellin S, Piccin L, Pigozzo J, Chiarion-Sileni V. Predictors of toxicity for metastatic melanoma patients treated with ipilimumab. J Immunother Cancer 2015;3(Suppl 2):P247

12. Fujisawa Y, Yoshino K, Otsuka A, Funakoshi T, Fujimura T, Yamamoto Y, Hata H, Gosho M, Tanaka R, Yamaguchi K, Nonomura Y, Hirai I, Furudate S, Okuhira H, Imafuku K, Aoki M, Matsushita S. Fluctuations in routine blood count might signal severe immune-related adverse events in melanoma patients treated with nivolumab. J Dermatol Sci 2017;88(2):225-31

13. Berman D, Parker SM, Siegel J, Chasalow SD, Weber J, Galbraith S, Targan SR, Wang HL. Blockade of cytotoxic T-lymphocyte antigen-4 by ipilimumab results in dysregulation of gastrointestinal immunity in patients with advanced melanoma. Cancer Immun 2010;10:11.

14. Shahabi V, Berman D, Chasalow SD, Wang L, Tsuchihashi Z, Hu B, Panting L, Jure-Kunkel M, Ji RR. Gene expression profiling of whole blood in ipilimumab-treated patients for identification of potential biomarkers of immune-related gastrointestinal adverse events. J Transl Med 2013;11:75.

15. Brahmer JR, Lacchetti C, Thompson JA. Management of immune-related adverse events in patients treated with immune checkpoint inhibitor therapy: american society of clinical oncology clinical practice guideline summary. J Oncol Pract 2018;14(4):247-9.

16. Beaven SW, Abreu MT. Biomarkers in inflammatory bowel disease. Curr Opin Gastroenterol 2004;20(4):318-27.

17. Geukes Foppen MH, Rozeman EA, van Wilpe S, Postma C, Snaebjornsson P, van Thienen JV, van Leerdam ME, van den Heuvel M, Blank CU, van Dieren J, Haanen JBAG. Immune checkpoint inhibition-related colitis: symptoms, endoscopic features, histology and response to management. ESMO Open 2018;3(1):e000278.

18. Gupta A, De Felice KM, Loftus EV, Jr., Khanna S. Systematic review: colitis associated with anti-CTLA-4 therapy. Aliment Pharmacol Ther 2015;42(4):406-17.

19. Som A, Mandaliya R, Alsaadi D, Farshidpour M, Charabaty A, Malhotra N, Mattar MC. Immune checkpoint inhibitor-induced colitis: A comprehensive review. World J Clin Cases 2019;7(4):405-18.

20. Gonzalez RS, Salaria SN, Bohannon CD, Huber AR, Feely MM, Shi C. PD-1 inhibitor gastroenterocolitis: case series and ap- praisal of 'immunomodulatory gastroenterocolitis'. Histopathology 2017;70(4):558-67.

21. Assarzadegan N, Montgomery E, Anders RA. Immune checkpoint inhibitor colitis: the flip side of the wonder drugs. Virchows Arch 2018;472(1):125-33

22. Oble DA, Mino-Kenudson M, Goldsmith J, Hodi FS, Seliem RM, Dranoff G, Mihm M, Hasserjian R, Lauwers GY. Alpha-CTLA-4 mAb-associated panenteritis: a histologic and immunohistochemical analysis. Am J Surg Pathol 2008;32(8):1130-7.

23. Huffman BM, Kottschade LA, Kamath PS, Markovic SN. Hepatotoxicity after immune checkpoint inhibitor therapy in melanoma: natural progression and management. Am J Clin Oncol 2018;41(8):760-5.

24. Johncilla M, Misdraji J, Pratt DS, Agoston AT, Lauwers GY, Srivastava A, Doyle LA. Ipilimumab-associated hepatitis: clinicopathologic characterization in a series of 11 cases. Am J Surg Pathol 2015;39(8):1075-84.

25. Winer A, Bodor $\mathrm{JN}$, Borghaei H. Identifying and managing the adverse effects of immune checkpoint blockade. J Thorac Dis 2018;10(Suppl 3):S480-9.

26. Rajarathnam K, Schnoor M, Richardson RM, Rajagopal S. How do chemokines navigate neutrophils to the target site: dissecting the structural mechanisms and signaling pathways. Cell Signal 2019;54:69-80.

27. Lim SY, Lee JH, Gide TN, Menzies AM, Guminski A, Carlino MS, Breen EJ, Yang JYH, Ghazanfar S, Kefford RF, Scolyer RA, Long, Rizos. Circulating cytokines predict immune-related toxicity in melanoma patients receiving anti-PD-1-based immunotherapy. Clin Cancer Res 2019;25(5):1557-63.

28. Schoenfeld JD, Nishino M, Severgnini M, Manos M, Mak RH, Hodi FS. Pneumonitis resulting from radiation and immune checkpoint blockade illustrates characteristic clinical, radiologic and circulating biomarker features. J Immunother Cancer 2019;7(1):112.

29. Naidoo J, Wang X, Woo KM, Iyriboz T, Halpenny D, Cunningham J, Chaft JE, Segal NH, Callahan MK, Lesokhin AM, Rosenberg J, Voss MH1, Rudin CM, Rizvi H, Hou X, Rodriguez K, Albano M1, Gordon RA, Leduc C, Rekhtman N, Harris B, Menzies AM, Guminski AD, Carlino MS, Kong BY, Wolchok JD, Postow MA, Long GV, Hellmann MD. Pneumonitis in patients treated with anti-programmed death-1/ programmed death ligand 1 therapy. J Clin Oncol 2017;35(7):709-17.

30. Weber JS, Yang JC, Atkins MB, Disis ML. Toxicities of immunotherapy for the practitioner. J Clin Oncol 2015;33(18):2092-9.

31. Chang J, Tran J, Kamel D, Basu A. Nivolumab-induced hypophysitis leading to hypopituitarism and secondary empty sella syndrome in a patient with non-small cell lung cancer. BMJ Case Rep 2019;12(3):e228135.

32. Joshi MN, Whitelaw BC, Carroll PV. Mechanisms in endocrinology: hypophysitis: diagnosis and treatment. Eur J Endocrinol 2018;179(3):R151-r63.

33. Prabhakar VK, Shalet SM. Aetiology, diagnosis, and management of hypopituitarism in adult life. Postgrad Med J 2006;82(966):259-66.

34. Caturegli P, Lupi I, Landek-Salgado M, Kimura H, Rose NR. Pituitary autoimmunity: 30 years later. Autoimmun Rev 2008;7(8):631-7.

35. Cukier P, Santini FC, Scaranti M, Hoff AO. Endocrine side effects of cancer immunotherapy. Endocr Relat Cancer 2017;24(12):T331-t47. 36. Zhao C, Tella SH, Del Rivero J, Kommalapati A, Ebenuwa I, Gul- 
ley J, Strauss J, Brownell I. Anti-PD-L1 Treatment induced central diabetes insipidus. J Clin Endocrinol Metab 2018;103(2):365-9.

37. Faje A. Hypophysitis: evaluation and management. Clin Diabetes Endocrinol 2016;2:15.

38. Caturegli P, Di Dalmazi G, Lombardi M, Grosso F, Larman HB, Larman T, Taverna G, Cosottini M, Lupi I. Hypophysitis secondary to cytotoxic t-lymphocyte-associated protein 4 blockade: insights into pathogenesis from an autopsy series. Am J Pathol 2016;186(12):322535.

39. Byun DJ, Wolchok JD, Rosenberg LM, Girotra M. Cancer immunotherapy - immune checkpoint blockade and associated endocrinopathies. Nat Rev Endocrinol 2017;13(4):195-207.

40. Lee H, Hodi FS, Giobbie-Hurder A, Ott PA, Buchbinder EI, Haq R, Tolaney S, Barroso-Sousa R, Zhang K, Donahue H, Davis M, Gargano ME, Kelley KM, Carroll RS, Kaiser UB, Min L. Characterization of thyroid disorders in patients receiving immune checkpoint inhibition therapy. Cancer Immunol Res 2017;5(12):1133-40.

41. Barroso-Sousa R, Barry WT, Garrido-Castro AC, Hodi FS, Min L, Krop IE, Tolaney SM. Incidence of endocrine dysfunction following the use of different immune checkpoint inhibitor regimens: a systematic review and meta-analysis. JAMA Oncol 2018;4(2):173-82.

42. Maekura T, Naito M, Tahara M, Ikegami N, Kimura Y, Sonobe S, Kobayashi T, Tsuji T, Minomo S, Tamiya A, Atagi S. Predictive factors of nivolumab-induced hypothyroidism in patients with non-small cell lung cancer. In Vivo 2017;31(5):1035-9.

43. Kostoglou-Athanassiou I, Ntalles K. Hypothyroidism - new aspects of an old disease. Hippokratia 2010;14(2):82-7.

44. González-Rodríguez E, Rodríguez-Abreu D. Immune checkpoint Inhibitors: review and management of endocrine adverse events. Oncologist 2016;21(7):804-16.

45. Barroso-Sousa R, Ott PA, Hodi FS, Kaiser UB, Tolaney SM, Min L. Endocrine dysfunction induced by immune checkpoint inhibitors: practical recommendations for diagnosis and clinical management. Cancer 2018;124(6):1111-21.

46. Napier C, Pearce SH. Autoimmune Addison's disease. Presse Med 2012;41(12 p 2):e626-35.

47. Shariff AI, D'Alessio DA. Primary adrenal insufficiency from immune checkpoint inhibitors. AACE Clinical Case Reports 2018;4(3): e232-e4.

48. Hughes J, Vudattu N, Sznol M, Gettinger S, Kluger H, Lupsa B, Kevan C. Herold. Precipitation of autoimmune diabetes with anti-PD-1 immunotherapy. Diabetes Care 2015;38(4):e55-7.

49. Mamlouk O, Selamet U, Machado S, Abdelrahim M, Glass WF, Tchakarov A, Gaber L, Lahoti A, Workeneh B, Chen S, Lin J, Abdel-Wahab N, Tayar J, Lu H, Suarez-Almazor M, Tannir N, Yee C, Diab A, Abudayyeh A. Nephrotoxicity of immune checkpoint inhibitors beyond tubulointerstitial nephritis: single-center experience. J Immunother Cancer 2019;7(1):2.

50. Wanchoo R, Karam S, Uppal NN, Barta VS, Deray G, Devoe C, Launay-Vacher V, Jhaveri KD; Cancer and kidney international network workgroup on immune checkpoint inhibitors. Adverse renal effects of immune checkpoint inhibitors: a narrative review. Am J Nephrol 2017;45(2):160-9.

51. Perazella MA, Shirali AC. Nephrotoxicity of cancer immunothera- pies: past, present and future. J Am Soc Nephrol 2018;29(8):2039-52. 52. Cortazar FB, Marrone KA, Troxell ML, Ralto KM, Hoenig MP, Brahmer JR, Le DT2, Lipson EJ, Glezerman IG, Wolchok J, Cornell LD, Feldman P, Stokes MB, Zapata SA, Hodi FS, Ott PA, Yamashita M, Leaf DE. Clinicopathological features of acute kidney injury associated with immune checkpoint inhibitors. Kidney Int 2016;90(3):638-47.

53. Banks PA, Bollen TL, Dervenis C, Gooszen HG, Johnson CD, Sarr MG, Tsiotos GG, Vege SS; Acute Pancreatitis Classification Working Group. Classification of acute pancreatitis--2012: revision of the Atlanta classification and definitions by international consensus. Gut 2013;62(1):102-11.

54. Gullo L. Day-to-day variations of serum pancreatic enzymes in benign pancreatic hyperenzymemia. Clin Gastroenterol Hepatol 2007;5(1):70-4.

55. Laubli H, Balmelli C, Bossard M, Pfister O, Glatz K, Zippelius A. Acute heart failure due to autoimmune myocarditis under pembrolizumab treatment for metastatic melanoma. J Immunother Cancer 2015;3:11.

56. Johnson DB, Balko JM, Compton ML, Chalkias S, Gorham J, Xu Y, Hicks M, Puzanov I, Alexander MR, Bloomer TL, Becker JR, Slosky DA, Phillips EJ, Pilkinton MA, Craig-Owens L, Kola N, Plautz G, Reshef DS, Deutsch JS, Deering RP, Olenchock BA, Lichtman AH, Roden DM, Seidman CE, Koralnik IJ, Seidman JG, Hoffman RD, Taube JM, Diaz LA Jr, Anders RA, Sosman JA, Moslehi JJ. Fulminant myocarditis with combination immune checkpoint blockade. N Engl J Med 2016;375(18):1749-55.

57. Matson DR, Accola MA, Rehrauer WM, Corliss RF. Fatal myocarditis following treatment with the PD-1 inhibitor nivolumab. J Forensic Sci 2018;63(3):954-7.

58. Greenplate AR, Johnson DB, Roussel M, Savona MR, Sosman JA, Puzanov I, Ferrell PB, Irish JM. Myelodysplastic syndrome revealed by systems immunology in a melanoma patient undergoing anti-PD-1 therapy. Cancer Immunol Res 2016;4(6):474-80.

59. Kong BY, Micklethwaite KP, Swaminathan S, Kefford RF, Carlino MS. Autoimmune hemolytic anemia induced by anti-PD-1 therapy in metastatic melanoma. Melanoma Res 2016;26(2):202-4.

60. Inno A, Metro G, Bironzo P, Grimaldi AM, Grego E, Di Nunno V, Picasso V, Massari F, Gori S. Pathogenesis, clinical manifestations and management of immune checkpoint inhibitors toxicity. Tumori 2017;103(5):405-21.

61. Belkhir R, Burel SL, Dunogeant L, Marabelle A, Hollebecque A, Besse B, Leary A, Voisin AL, Pontoizeau C, Coutte L, Pertuiset E, Mouterde G, Fain O, Lambotte O, Mariette X. Rheumatoid arthritis and polymyalgia rheumatica occurring after immune checkpoint inhibitor treatment. Ann Rheum Dis 2017;76(10):1747-50.

62. Fellner A, Makranz C, Lotem M, Bokstein F, Taliansky A, Rosenberg S, Blumenthal DT, Mandel J, Fichman S, Kogan E, Steiner I, Siegal T, Lossos A, Yust-Katz S. Neurologic complications of immune checkpoint inhibitors. J Neurooncol 2018;137(3):601-9.

63. Johnson DB, Sullivan RJ, Menzies AM. Immune checkpoint inhibitors in challenging populations. Cancer 2017;123(11):1904-11.

64. Janssen I. The epidemiology of sarcopenia. Clin Geriatr Med 2011;27(3):355-63.

65. Revel M-P, Raynard B, Pigneur F, Palma MD, Toledano A, Deluche 
E, Romano O, Goldwasser F. Sarcopenia and toxicity of the anti-PD1 inhibitors in real-life lung cancer patients: results from the french nationwide SCAN study. J Clin Oncol 2018;36(15_suppl):e21066-e.

66. Heidelberger V, Goldwasser F, Kramkimel N, Jouinot A, Huillard O, Boudou-Rouquette P, Chanal J, Arrondeau J, Franck N, Alexandre
J, Blanchet B, Leroy K, Avril MF, Dupin N, Aractingi S. Sarcopenic overweight is associated with early acute limiting toxicity of anti-PD1 checkpoint inhibitors in melanoma patients. Invest New Drugs 2017;35(4):436-41. 